\section{A complex rearrangement involving three autosomes in a phenotypically normal male presenting with sterility}

SUMMARY This paper reports a rearrangement involving three autosomes: 11,12 , and 21 . The translocation carrier, a 31-year-old azoospermic male, is phenotypically normal.

Three-chromosome rearrangements associated with sterility in man are uncommon. With the exception of reports in chronic myeloid leukaemia, there have been 16 instances involving three chromosomes in published reports. This patient represents the seventeenth such case. In only three of the 16 previous reports had the rearrangements arisen de novo. ${ }^{1-3}$ In the remaining 13 cases, the subjects carrying the translocations were phenotypically normal females who were detected through a partially monosomic or trisomic child. This is apparently the first case of a phenotypically normal male presenting with azoospermia.

\section{Case report}

The proband was a 31-year-old male who presented with an 8-year history of sterility (fig 1). Physical examination showed a phenotypically normal male,

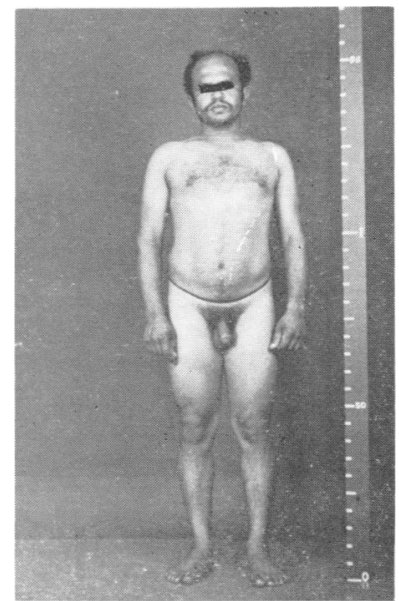

FIG 1 The patient, who appears normal except for the short stature.

Received for publication 24 February 1982.
$151 \mathrm{~cm}$ tall. Secondary sexual characteristics were normal and the testes and spermatic cord appeared normal.

The patient was the eldest of five sibs born to nonconsanguineous parents. The mother was 18 years old and the father 23 years old at the time of his conception. The mother had no history of abortion either before or after his birth. Three younger sibs were female and all of them are married, two of them with children. The youngest sib was a male who was not married at the time of this report. No family history of sterility could be elicited.

\section{LABORATORY FINDINGS}

The semen analyses showed azoospermia and a testicular biopsy showed diminished spermatogenesis (fig 2).

\section{CYTOGENETIC STUDIES}

Standard leucocyte microculture ${ }^{4}$ using peripheral blood was done and the chromosome preparations were $\mathrm{G}$ banded, ${ }^{5} \mathrm{C}$ banded (Scheres, ${ }^{6}$ modified in this laboratory), and silver stained for nucleolar organiser regions (Bloom and Goodpasture, ${ }^{7}$ modified by $\mathbf{G ~ R}$ Sutherland, personal communication to $\mathrm{D} S$ Krishnamurthy, 1980). Seventy-five metaphases were examined and all cells showed a partial deletion of the long arm of chromosome 11 and derivative chromosomes 12 and 21 (fig 3). No mosaicism for this rearrangement was observed. $G$ banding showed

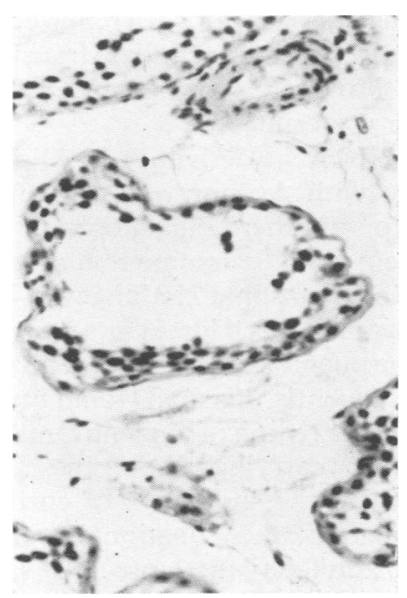

FIG 2 Testicular biopsy showing maturation arrest at secondary spermatocyte stage. (Haematoxylin-eosin. Original magnification $\times 400$.) 

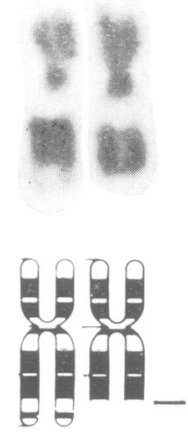

11
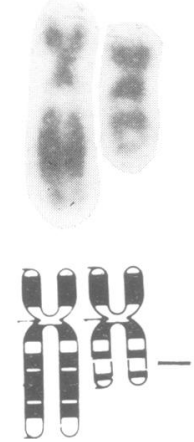

12
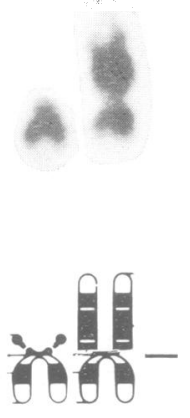

21
FIG $3 G$ banded partial karyotype showing deleted chromosome 11 and derivative chromosomes 12 and 21 and their diagrammatic representations.

that the proband's karyotype could be represented as: $46, \mathrm{XY}, \mathrm{t}(11 ; 12 ; 21)(11 \mathrm{pter} \rightarrow 11 \mathrm{q} 22: ; 12 \mathrm{pter} \rightarrow 12 \mathrm{q} 13$ $:: 11$ q22 $\rightarrow 11$ qter;21 qter $\rightarrow 21$ p11 $:: 12$ q13 $\rightarrow$ 12qter.) Silver staining was negative in the derivative chromosome 21 and at the point of deletion on the long arm of chromosome 11 . The absence of acrocentric associations with the deleted 11 confirmed that the satellite region from the derivative chromosome 21 had not been translocated to the deleted 11. Chromosomal analysis could not be done on the rest of the family members as they were uncooperative.

\section{Discussion}

To the best of our knowledge, sterility in males with chromosome rearrangements involving three or more chromosomes has not been reported previously. A review of reports on similar translocations in females has, however, shown reduced reproductive fitness but never sterility. ${ }^{8-18}$

The NORs from the derivative $12 ; 21$ chromosome did not stain with $\mathrm{Ag}$ nor were they found translocated onto another chromosome. It would, therefore, seem valid to assume that a portion of the short arm of chromosome 21 along with its nucleolar organiser region has been lost as an acentric fragment. This rearrangement would then be an unbalanced one and consequently this man would be monosomic for this particular region of chromosome 21 .

Apart from carrying the genes coding for ribosomal RNA, the short arm of chromosome 21 does not have any other functional genes attributed to it. It seems unlikely, therefore, that specific genes influencing the production and viability of sperm are lost through the monosomy and that this is the cause of sterility in this man. However, loss of chromatin material from this region of the chromosome would affect meiotic pairing. This would serve to form a chain rather than a ring configuration during zygotene. Such chain formation has been known to be responsible for male sterility in mice. ${ }^{19-21}$

The basis of sterility in the patient is essentially defective spermatogenesis leading to azoospermia. The complex structural rearrangement in the genome may impair zygotene and later stages of spermatogenesis because the derivative chromosomes fail to pair characteristically. It is, however, not clear why such complex rearrangements do not appear to cause sterility in females.

The authors acknowledge the financial support given by the Indian Council of Medical Research, New Delhi, India, to the project entitled 'Cytogenetic Investigations in Sterility'. They further wish to thank Mr D S Krishnamurthy for making available the methodology of the modified silver staining technique of G R Sutherland for this work. They gratefully acknowledge the valuable suggestions of Professor H Sharthchandra, Department of Microbiology, Indian Institute of Science, Bangalore, India.

ANN JoSePh AND IRene Manorama Thomas Cytogenetics Laboratory, Department of Anatomy, St John's Medical College, Bangalore 560 034, India.

\section{References}

1 Nuzzo F, Marini A, Baglioni C, Ford CE, de Carli L, Sereni LP. A case of multiple chromosomal rearrangements with persistence of fetal hemoglobin. Cytogenetics $1968 ; 7: 169-82$.

2 Taillemete JL, Baheux-Morlier G, Cathelineau L, Roux C. Cri-du-chat syndrome and complex chromosome rearrangement in a dizygotic twin. Ann Genet (Paris) 1973;16:127-30.

3 Buchnan PD, Rao KW, Doerr CL, Aylesworth AS. A complex translocation involving chromosomes 3,11 and 14 with an interstitial deletion, del (14) (q13q22) in a child with congenital glaucoma and cleft lip and palate. Birth Defects 1978;XIV: 317-22.

4 Arakaki DT, Sparkes RS. Microtechnique for culturing leukocytes from whole blood. Cytogenetics 1963;2:57-60.

5 Seabright M. A rapid banding technique for human chromosomes. Lancet 1971 ;ii: 971-2.

6 Scheres JMJC. Production of $\mathrm{C}$ and $\mathrm{T}$ bands in humans after heat treatment at high pH and staining with "stainsall". Hum Genet 1974;23:311-4.

7 Bloom SE, Goodpasture C. An improved technique for selective silver staining of nucleolar organiser regions in human chromosomes. Hum Genet 1976;34:199-206.

8 Fredga K, Hall B. A complex familial translocation involving chromosomes 5, 9, 13. Cytogenetics 1970;9: 294-306.

9 Allerdice PW, Miller OJ, Miller DA, Breg WR, Gendel E, Zelson C. Familial translocation involving chromosomes 6,14 , and 20 identified by quinacrine fluorescence. Humangenetik 1971 ;13:205-9. 
10 Creasy MR, Crolla JA, Daker MG. A familial reciprocal translocation between three chromosomes. Humangenetik 1974;24:303-8.

11 Schwinger E, Mikkelsen M, Niesen M. Familial balanced $(7 ; 11 ; 21)$ translocation and Down's syndrome in two siblings. Clin Genet 1975; 7:304-7.

12 Palmer CG, Poland C, Reed T, Kojetin J. Partial trisomy $11,46, \mathrm{XX},-3,-20,+\operatorname{der} 3,+\operatorname{der} 20, \mathrm{t}(3 ; 11 ; 20)$, resulting from a complex maternal rearrangement of chromosomes 3, 11 and 20. Hum Genet 1976;31:219-25.

13 Dallapiccola B, Bollea G, Mazzilli C, Gandini E. Complex translocation $\mathrm{t}(9 ; 21)(9 ; 22)(\mathrm{q} 12 \mathrm{p} 13)(\mathrm{q} 12 \mathrm{q} 11)$ in the family of a child with 9q trisomy syndrome. Hum Genet $1976 ; 33: 73-6$.

${ }_{14}$ Tanaka N, Ikeuchi T, Yara I, Kitahara K. Trisomy 9p due to maternal complex translocation involving chromosomes 4, 6 and 9. Jpn J Hum Genet 1977;21:261-8.

15 Hustinx TWJ, Nabben FAE, Scheres JMJC. Partial trisomy of chromosome 1 resulting from a complex maternal rearrangement of chromosomes 1,5 and $6 . \mathrm{Am} \mathrm{J}$ Med Genet 1979;3:353-8.

16 Fernandez E, Mila M. Maternal translocation $(1 ; 8 ; 15)$ with a 8qter trisomy in her daughter. J Genet Hum 1980; 28:361-6.

17 Tabor A, Jensen LK, Lundsteen C, Niebuhr E. A 5; 7, 5;12 double reciprocal translocation in a normal mother and a $5 ; 7$ translocation with a recombinant chromosome 5 in her normal child. J Med Genet $1981 ; 18$ :307-9.

18 Muneer RS, Donaldson DL, Rennert OM. Complex balanced translocation of chromosomes 2, 3 and 13 . Hum Genet $1981 ; 59: 182-4$.

19 Lyon MF, Meredith R. Autosomal translocations carrying male sterility and viable aneuploidy in the mouse. Cytogenetics 1966;5:335-54.

20 Cacheiro NL, Russell LB, Swartout MS. Translocations, the predominant cause of total sterility in sons of mice treated with mutagens. Genetics $1974 ; 76: 73-91$.

21 Searle AG. Nature and consequences of induced chromosome damage in mammals. Genetics 1974;78:173-86.

Requests for reprints to Dr I M Thomas, Cytogenetics Laboratory, Department of Anatomy, St John's Medical College, Bangalore 560 034, India.

\section{Yq- in a child with livedo}

\section{reticularis, snub nose, microcephaly, and profound mental retardation*}

SUMMARY A child with terminal deletion of the long arm of the $\mathrm{Y}$ chromosome $(\mathrm{Yq}-)$ presented with marked livedo reticularis, snub nose, microcephaly, short stature, and other dysmorphic features. He was profoundly mentally

*Presented in part at the 49th Annual Meeting of the Genetics Society of America, Boulder, Colorado, 17-20 August 1980.

Supported in part by a Special Project Grant from the Maternal and Child Health Services, Public Health Service, United States Department of Health and Welfare, and the Division for Maternal and Child Health Services, Bureau for Health Services, Department for Human Resources, Commonwealth of Kentucky.

Received for publication 11 December 1981. retarded. Most of the patients with $\mathrm{Yq}-$ have been reported as having varying dysmorphic features, mental retardation, and short stature. This child, in addition to the above, has livedo reticularis and microcephaly. He was of normal birthweight and, therefore, does not come into the syndrome of microcephaly, snub nose, livedo reticularis, and low birthweight dwarfism. Further information on Yq - should be obtained to ascertain if consistent patterns of abnormalities exist.

Cases with terminal deletion of the long arm of the $\mathrm{Y}$ chromosome $(\mathrm{Yq}-$ ) have presented with a range of findings, from normal intelligence and normal male development, ${ }^{1}$ normal fertility, ${ }^{2}$ aspermia ${ }^{3}$ varying dysmorphic features (major and minor), ${ }^{4}$ mental retardation, ${ }^{346}$ and short stature ${ }^{135-7}$ (table). In only one of these was the $\mathrm{Yq}-$ familial. $^{8}$ The case described here, in addition to short stature, congenital abnormalities, and mental retardation, had marked livedo reticularis and microcephaly.

\section{Case report}

The proband (fig 1), born on 18.7.71 and seen at 5 years 7 months of age and at 8 years 7 months of age, was the youngest and third-born child. At the time of his birth, his father and mother were 26 and 27 years of age, respectively. The pregnancy and delivery were uncomplicated and the birthweight was 3200 g. Mild respiratory distress developed 24 hours after birth. His head circumference at birth was reported to be $35 \mathrm{~cm}$. His head circumference at 10 months of age was $43 \mathrm{~cm}$, and at 23 months of age

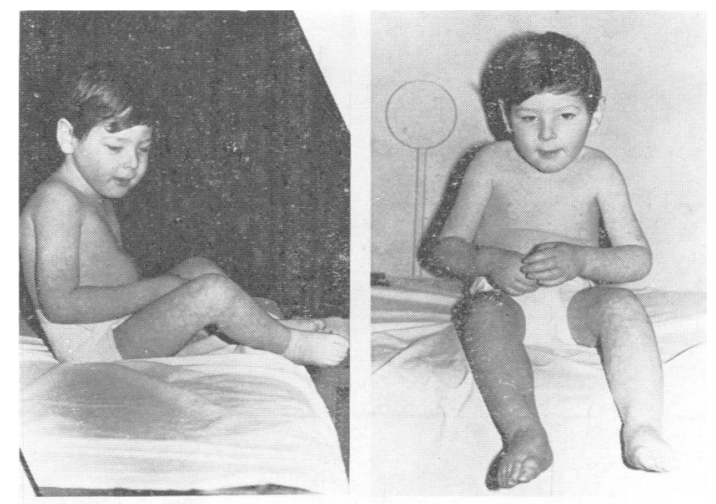

FIG 1 Proband. Note livedo reticularis. 